\title{
Anti-HSV-1 activity of Aspergillipeptide D, a cyclic pentapeptide isolated from fungus Aspergillus sp. SCSIO 41501
}

Zhaoyang Wang ${ }^{1 \dagger}$, Jiaoyan Jia ${ }^{1 \dagger}$, Lu Wang ${ }^{1}$, Feng Li ${ }^{1}$, Yiliang Wang ${ }^{1}$, Yuzhou Jiang ${ }^{1}$, Xiaowei Song ${ }^{1}$, Shurong Qin', Kai Zheng ${ }^{2}$, Ju Ye ${ }^{3}$, Zhe Ren ${ }^{1 *}$, Yifei Wang ${ }^{1 *}$ and Shuhua Qi ${ }^{4^{*}}$

\begin{abstract}
Background: Herpes simplex virus 1, an enveloped DNA virus belonging to the Herpesviridae family, spreads to neurons and causes pathological changes in the central nervous system. The purpose of this study was to investigate the potency and mechanism of antiviral activity of Aspergillipeptide D, a cyclic pentapeptide isolated from a culture broth of marine gorgonian-derived fungus Aspergillus sp. SCSIO 41501, At present, there are many studies on the anti-tumor, anti-clotting, anti-oxidant and immunoinflammatory effects of Aspergillipeptide $D$, but little research has been done on the anti-HSV-1 activity of Aspergillipeptide D.
\end{abstract}

Methods: The anti-HSV-1 activity of Aspergillipeptide D was evaluated by plaque reduction assay. The mechanism of action against HSV-1 was determined from the effective stage. Then we assayed the viral DNA replication, viral RNA synthesis and protein expression, respectively. We also identified the proteins that interact with gB by mass spectrometry, and assayed the effect of Aspergillipeptide D on the interaction between the virus gB protein and cell proteins.

Results: Plaque reduction experiments showed that Aspergillipeptide D did not affect HSV-1 early infection events, including viral inactivation, attachment and penetration. Interestingly, Aspergillipeptide D dramatically reduced both the gene and protein levels of viral late protein $\mathrm{gB}$, and suppressed its location in the endoplasmic reticulum and Golgi apparatus. In contrast, overexpression of gB restored viral production. Finally, proteomic analysis revealed that the numbers of cellular proteins that interacted with $\mathrm{gB}$ protein was largely decreased by Aspergillipeptide $\mathrm{D}$. These results suggested that Aspergillipeptide D inhibited gB function to affect HSV-1 intercellular spread.

Conclusions: Our results indicated that Aspergillipeptide D might be a potential candidate for HSV-1 therapy, especially for ACV-resistant strains.

Keywords: HSV-1, Aspergillipeptide D, Marine peptide, Glycoprotein B

\footnotetext{
*Correspondence: JNU1906@163.com; twang-yf@163.com;

shuhuaqi@scsio.ac.cn

${ }^{+}$Zhaoyang Wang and Jiaoyan Jia contributed equally to this work.

'Guangzhou Jinan Biomedicine Research and Development Center, National

Engineering Research Center of Genetic Medicine, Jinan University,

Guangzhou, Guangdong, China

${ }^{4}$ CAS Key Laboratory of Tropical Marine Bio-resources and Ecology, South

China Sea Institute of Oceanology Chinese Academy of Sciences, 164 West

Xingang Road, Guangzhou 510301, Guangdong, China

Full list of author information is available at the end of the article
}

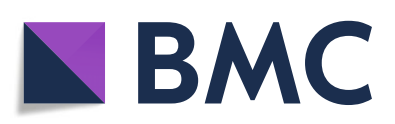

(- The Author(s). 2020 Open Access This article is licensed under a Creative Commons Attribution 4.0 International License, which permits use, sharing, adaptation, distribution and reproduction in any medium or format, as long as you give appropriate credit to the original author(s) and the source, provide a link to the Creative Commons licence, and indicate if changes were made. The images or other third party material in this article are included in the article's Creative Commons licence, unless indicated otherwise in a credit line to the material. If material is not included in the article's Creative Commons licence and your intended use is not permitted by statutory regulation or exceeds the permitted use, you will need to obtain permission directly from the copyright holder. To view a copy of this licence, visit http://creativecommons.org/licenses/by/4.0/. The Creative Commons Public Domain Dedication waiver (http://creativecommons.org/publicdomain/zero/1.0/) applies to the data made available in this article, unless otherwise stated in a credit line to the data. 


\section{Background}

Herpes simplex virus 1 (HSV-1), an enveloped DNA virus belonging to the Herpesviridae family, spreads to neurons and causes pathological changes in the central nervous system [1]. HSV-1 virus particle consists of a core and a linear double-stranded DNA enclosed in a capsid; an outer envelope containing various glycoproteins covers tegument proteins, which are exterior to the viral capsid [2]. HSV-1 envelopes contain at least 14 different proteins [3], but only four of them, gB, gD, gH and $\mathrm{gL}$ are required for entry, which are established by analyzing the infectivity of $\mathrm{HSV}-1$ mutants containing single gene deletions [4-7] . gB is the most highly conserved glycoprotein, and is a class III viral fusion protein involved directly in the viral and host cell membrane interaction and fusion $[8,9]$.

Nowadays most of antiviral drugs applied in clinic are largely nucleic acid analogs, all of which target viral DNA replication process. One representative example is Acyclovir (ACV). As a consequence, drug-resistant HSV strains, especially ACV-resistant HSV strains, found frequently [10]. Therefore, the development of novel anti-HSV agents with different mechanisms of action is urgent.

Many marine peptides, obtained from seaweeds, fishes, mollusk, crustaceans, crabs and marine bacteria and fungi, show various biological activities such as antitumor, anti-virus, anti-oxidant, immunoinflammatory effects and other pharmaceutical properties based on their structural characteristics, amino acid composition and sequences [11-13]. In our previous study, Aspergillipeptide $\mathrm{D}$, a new cyclic pentapeptide, was obtained from the fungal strain Aspergillus sp. SCSIO 41501 as white solid with the molecular formula of $\mathrm{C} 40 \mathrm{H} 49 \mathrm{~N} 5 \mathrm{O} 8$ (Fig. 1a)
[14]. In this study, we further investigated the potency and mechanism of antiviral activity of Aspergillipeptide D against HSV-1 and ACV-resistant strains.

\section{Main text \\ Methods \\ Chemicals and reagents}

The cyclic pentapeptide, Aspergillipeptide D, was isolated from the fungal strain Aspergillus SCSIO 41501 [14]. ACV (acyclovir) and 2-(2,5-dimethyl-2-thiazolyl)-2, 5-diphenyl-2H-tetrazolium bromide (MTT) were obtained from SigmaAldrich (St. Louis, MO, USA). Trizol Reagent was purchased from Invitrogen (Carlsbad, CA, USA). Dulbecco's modified Eagle medium (DMEM), fetal bovine serum (FBS), and penicillin-streptomycin were bought from Gibco-BRL (Gland Island, NY, USA). Aspergillipeptide $\mathrm{D}$ and $\mathrm{ACV}$ were dissolved in dimethylsulfoxide (DMSO), and the final concentrations of DMSO were less than $0.1 \%$. Restriction enzymes were purchased from Takara Bio (Shiga, Japan).

\section{Cells and viruses}

African green monkey kidney cells (Vero; ATCC CCL81) were cultured in DMEM supplemented with $10 \%$ heat-inactivated FBS. The maintenance medium used for virus dilutions was DMEM supplemented with 2\% heat-inactivated FBS. HSV-1/F (ATCC VR-733) was preserved in our lab. HSV-1/Blue, a TK mutant derived from HSV-1 (KOS) [15], two ACV-resistant clinical HSV-1 strains (HSV-1/106 and HSV-1/153) were a kind gift from Tao Peng (Guangzhou Institutes of Biomedicine and Health, Chinese Academy of Sciences). All

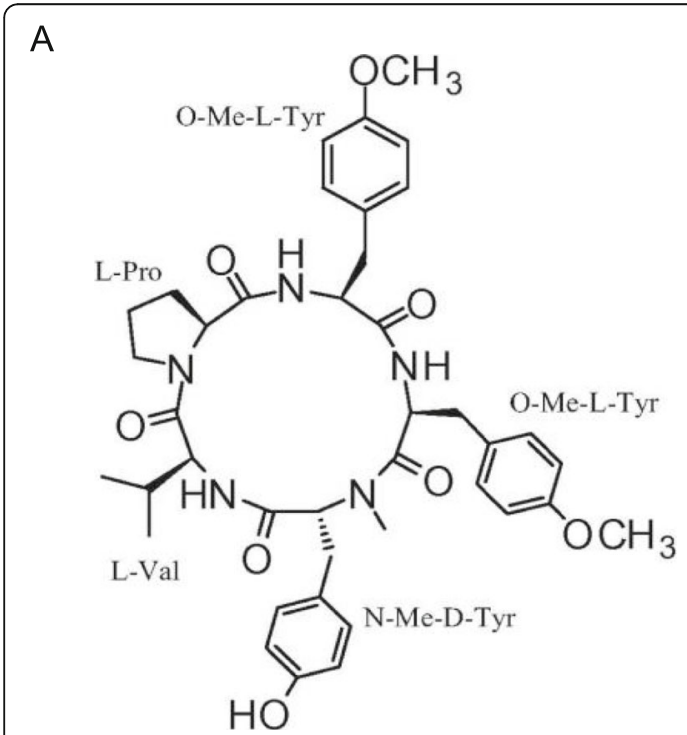

B

Fig. 1 Cytotoxicity of Aspergillipeptide D. a The structure formula of Aspergillipeptide D. b Vero cells were treated with different concentrations of AspergillipeptideD for $48 \mathrm{~h}$, and MTT method was performed to calculate the cell survival rate. Data are mean \pm SD $(n=3)$ 
viruses were propagated in Vero cells and stored at $-80^{\circ} \mathrm{C}$ until further use.

\section{MTT assay}

The MTT assay was performed according to the standard protocol. Briefly, Vero cells were cultured in 96-well plates. After the cell confluence reached 90\%, various concentrations of compound were added to the plate, with each concentration having three replicates. After $48 \mathrm{~h}$ of incubation, $10 \mu \mathrm{l} \mathrm{MTT}$ solution $(5 \mathrm{mg} / \mathrm{mL})$ was added to each well, and the plate was incubated for $4 \mathrm{~h}$ in the dark. Then, the MTT solution was discarded, and $100 \mu \mathrm{l}$ DMSO was added to each well. Plates were incubated for $15 \mathrm{~min}$ at room temperature with gently shaking. The optical density (OD) at 570 and $630 \mathrm{~nm}$ was measured for each well with an enzyme immunoassay reader (Bio-Rad, Hercules, CA, USA). The 50\% cytotoxicity concentration (CC50) was defined as the concentration to reduce $50 \%$ cell viability.

\section{Viral titer determination using plaque assay}

Vero cells were cultured in 96-well plates. And the next day ten-fold serial dilutions of with and without treatment of extracts of HSV-1 were prepared prior to infection. Vero cell monolayers were then infected with different dilutions of $100 \mu \mathrm{HSV}-1$ and allowed to adsorb for $2 \mathrm{~h}$ at $37{ }^{\circ} \mathrm{C}$ and $5 \% \mathrm{CO}_{2}$. Unabsorbed viruses were aspirated, and plates were then overlaid with a nutrient medium-containing agar and incubated at $37^{\circ} \mathrm{C}$ and $5 \% \mathrm{CO}_{2}$ for 3 days. Plaques were visualized by staining cells with crystal violet and counting within $50 \mathrm{~h}$. The plaque assay was carried out in triplicate. Virus was quantified by serial dilution and titration assay. The TCID50 (50\% tissue culture infectious dose) was calculated using the formula of Reed and Muench method [16]:

$\log 1050 \%$ end point dilution $=\log 10$ of dilution showing a mortality next above 50\% - (difference of logarithms $\times$ logarithm of dilution factor).

Difference of logarithms $=[$ (mortality at dilution next above 50\%)-50\%] / [(mortality next above 50\%) - (mortality next below 50\%)].

\section{Plaque reduction assay}

Experimental wells of 24-well plates containing confluent monolayers of Vero cells were infected with virus suspensions to produce 50 plaques per well. After $2 \mathrm{~h}$ incubation at $37^{\circ} \mathrm{C}$ and $5 \% \mathrm{CO} 2$, unabsorbed virions were aspirated. Aspergillipeptide D solution $(25 \mu \mathrm{M}, 12.5 \mu \mathrm{M}$, $6.25 \mu \mathrm{M}, 3.125 \mu \mathrm{M}, 1.5625 \mu \mathrm{M}$, and $0.78125 \mu \mathrm{M}$, respectively) was then added to the appropriate wells, followed by nutrient medium containing agar; the plates were incubated at $37^{\circ} \mathrm{C}$ and $5 \% \mathrm{CO} 2$ for 3 days. Plaques were counted as described above. The antiviral activity was calculated by the following formula:

$$
\text { Antiviral activity }(\%)=\frac{\text { plaque number }(\text { control })-\text { plaque number }(\text { assay })}{\text { plaque number }(\text { control })} \times 100 \%
$$

\section{Virus inactivation assay}

Culture Vero cells into 24 -well plates $\left(1.5^{*} 10^{5}\right.$ cells/well), and the next day $100 \mu \mathrm{l}$ of virus inoculum (50 PFUs per well) and $100 \mu \mathrm{l}$ of Aspergillipeptide D solution (different concentrations) were mixed and incubated for $2 \mathrm{~h}$ at $37^{\circ} \mathrm{C}$. Then the mixture was added into cell wells and incubated at $37^{\circ} \mathrm{C}$ for $2 \mathrm{~h}$. The inoculated were removed. Cells were replenished with cover layer and 3 days later were fixed, stained as described above.

\section{Virus attachment assay}

Culture Vero cells into 24 -well plates $\left(1.5^{*} 10^{5}\right.$ cells/well $)$, and the next day cells were pre-cooled at $4{ }^{\circ} \mathrm{C}$ for $1 \mathrm{~h}$ and washed by cold PBS. Virus inoculum (50 PFUs per well) and Aspergillipeptide D at indicated concentrations were added into cell wells, and the mixture was incubated at $4{ }^{\circ} \mathrm{C}$ for another $2 \mathrm{~h}$ to allow virus attaching to the cells. The virus inoculum was removed. Cells were replenished with cover layer and 3 days later were fixed, stained as described above.

\section{Virus penetration assay}

Culture Vero cells into 24 -well plates $\left(1.5^{*} 10^{5}\right.$ cells/well), and the next day cells were pre-cool at $4{ }^{\circ} \mathrm{C}$ for $1 \mathrm{~h}$ and washed by cold PBS then infected by virus (50 PFUs per well) for another $2 \mathrm{~h}$ at $4{ }^{\circ} \mathrm{C}$ to allow virus attaching to the cells. After that, the virus inoculum was removed, and cells were washed by cold PBS. Then different concentrations of Aspergillipeptide $\mathrm{D}$ were added and incubated at $37^{\circ} \mathrm{C}$ for $10 \mathrm{~min}$ to maximize virus penetration. After incubation, $\mathrm{PBS}(\mathrm{pH}=3)$ was added into every well for $1 \mathrm{~min}$ to inactive the virus which failed to penetrate the cells. After that, the solution was neutralized and the neutral PBS was removed. Cells were replenished with cover layer and 3 days later were fixed, stained as described above.

\section{Treatment effects after virus infection}

Vero cells were cultured in 24-well plates. And next day cells were infected with HSV-1 (50 PFUs per well) for 2 $\mathrm{h}$ at $37^{\circ} \mathrm{C}$. After infection, the virus inoculum was removed, and cells were washed by PBS, and overlaid with Aspergillipeptide $\mathrm{D}$ at the indicated concentrations. After 3 days, cells were fixed, stained as described above.

\section{The analysis of HSV-1 DNA synthesis}

Vero cells were cultured in 24-well plates. And next day cells infected with HSV-1 $(\mathrm{MOI}=3)$ were incubated with 
or without Aspergillipeptide D $(25 \mu \mathrm{M})$ for $15 \mathrm{~h}$. Viral DNA was extracted using GeneJET Viral DNA and RNA Purification Kit (Thermo). RT-PCR assay was used to quantify the viral DNA. Then the HSV-1 genome copy numbers were expressed relative to the virus control groups. The primer pairs are as follow: $U L 47$ (F: 5'GACGTA CGCGAT GAG ATC AA -3', R: 5'-GTT ACC GGA TTA CGG GGA CT-3').

\section{Real-time PCR}

Vero cells were cultured in 6-well plates. And next day cells infected with HSV-1 $(\mathrm{MOI}=3)$ were incubated with Aspergillipeptide D $(25 \mu \mathrm{M})$ for $3,6,9 \mathrm{~h}$, respectively. Total RNA was isolated using Trizol (Invitrogen) and subjected to cDNA synthesis using a PrimeScript RT reagent kit (Takara). Real-time PCR (RT-PCR) was conducted to determine the expression levels of immediate early (IE) gene UL54, early (E) gene UL52 and late (L) gene UL27 of HSV-1/F and HSV-1/106 at 3, 6 and $9 \mathrm{~h}$ pi., respectively. The primer pairs were the same as described before [17].

\section{Immunofluorescence assay}

Vero cells were cultured in confocal dish, next day cells infected with HSV-1 $(\mathrm{MOI}=3)$ at $37^{\circ} \mathrm{C}$ for $2 \mathrm{~h}$ for viral adsorption. Cells were transferred into main medium with or without $25 \mu \mathrm{M}$ Aspergillipeptides D and incubated for 9 h.p.i. Cells were fixed for 15 min with $4 \%$ paraformaldehyde (PFA) and permeabilized with $0.02 \%$ Triton X-100, both in $\mathrm{PBS}$, and subsequently incubated with anti-gB antibody (Abcam) for $60 \mathrm{~min}$ and Alexa Fluor 488(1:1000) secondary antibody (Invitrogen) for $60 \mathrm{~min}$. Then, the cells were stained with Golgi-Tracker Red or ER-Tracker Red (Beyotime, China). After each step the slides were washed repeatedly with PBS, and finally they were preserved with PBS. The additional nuclear staining with 4,6-diamidino-2-phenylindole (DAPI, Molecular Probes) was per-formed for 20 min. Fluorescence was recorded in a confocal laser scan microscope (LSM 510 meta; Zeiss) [17].

\section{Western blotting}

Vero cells were seeded in $60 \mathrm{~mm}$ cell culture dish with the density of $1.5 \times 10^{6}$ cells/ dish. After $24 \mathrm{~h}$, cells were infected with HSV-1 $(\mathrm{MOI}=3)$ at $37^{\circ} \mathrm{C}$ for $2 \mathrm{~h}$. DMEM maintenance medium containing Aspergillipeptides D $(25 \mu \mathrm{M})$ was added. At 6 and $9 \mathrm{~h}$ post-infection, the cells were washed three times with PBS, and were lysed using RIPA buffer (Beyotime). The equal amount $(40 \mu \mathrm{g} / \mathrm{sam}-$ ple) proteins were subjected to Western Blot analysis. A primary antibody against HSV-1 ICP0 (abcam1:1000), ICP8 (abcam 1:8000), VP5 (santa1:1000), gB (abcam1: 1000) and gD (abcam1:1000) was used to detect the content changes of immediate early, early and late protein [18].

\section{Co-immunoprecipitation (co-IP) and LC-MS analysis}

Vero cells were seeded in $100 \mathrm{~mm}$ cell culture dish with the density of $3 \times 10^{6}$ cells/ dish. After $24 \mathrm{~h}$, cells were treated with Aspergillipeptide D $(25 \mu \mathrm{M})$ and infected with HSV-1 $(\mathrm{MOI}=3)$ for $9 \mathrm{~h}$. The cells were then lysed and the protein concentrations were measured and adjusted to $1 \mathrm{mg} / \mathrm{ml}$. The lysate was precleared by adding $1.0 \mu \mathrm{g}$ of the appropriate control IgG (normal mouse or rabbit IgG, corresponding to the host species of the primary antibody), together with $20 \mu \mathrm{l}$ of resuspended volume of Protein A/G PLUSA agarose. Afterwards, the mixture was incubated at $4{ }^{\circ} \mathrm{C}$ for $30 \mathrm{~min}$. The optimal dilution of primary antibody was added to the cell lysates (supernatant), incubated for $1 \mathrm{~h}$ at $4{ }^{\circ} \mathrm{C}$, and then incubated at $4{ }^{\circ} \mathrm{C}$ overnight with $30 \mu \mathrm{l}$ of resuspended volume of Protein A/G PLUS-Agarose. Next, the immunoprecipitation was collected, washed with PBS, and resuspended in $20 \mu \mathrm{l} 1 \times$ SDS PAGE buffer (Beyotime, China). The LC-MS Analysis were provided by the BGI (China).

\section{Statistical analysis}

Results were calculated as the mean $\pm \mathrm{SD}$, and statistical significance were determined by the Student's t test. $P$ values $(\mathrm{P})<0.05$ were considered statistically significant.

\section{Results}

\section{Cytotoxicity and anti-HSV-1 activity of Aspergillipeptide D}

To examine the cytotoxic effect of Aspergillipeptide D on Vero cells, MTT assay was used. A significant reduction of cell vitality was observed at concentration > $25 \mu \mathrm{M}$, corresponding with the CC50 value as $208.723 \pm$ $9.717 \mu \mathrm{M}$ (Fig. 1b). Next, the antiviral activities of Aspergillipeptide D against $\mathrm{HSV}-1 / \mathrm{F}$ and three ACV-resistant strains, including HSV-1/Blue, a TK mutant derived from HSV-1, and two clinical HSV-1 strains HSV-1/106 and HSV-1/153 [19], were monitored by plaque reduction assay (Fig. 2), which clearly showed that Aspergillipeptide $\mathrm{D}$ inhibits both $\mathrm{HSV}-1 / \mathrm{F}$ and $\mathrm{ACV}$-resistant strains infection in a dose-dependent manner. As shown in Table 1, the 50\% effective concentrations (EC50) for Aspergillipeptide D and ACV to inhibit HSV-1/F were $7.928 \pm 0.511 \mu \mathrm{M}$ and $3.606 \pm 0.302 \mu \mathrm{M}$, respectively. The EC50 values of Aspergillipeptide D against HSV-1/ 153, HSV-1/106, and HSV-1/Blue were $8.277 \pm$ $1.249 \mu \mathrm{M}, 10.486 \pm 0.929 \mu \mathrm{M}$, and $7.9875 \pm 0.616 \mu \mathrm{M}$, respectively. In contrast, the EC50 of ACV against all the three resistant strains were more than $40 \mu \mathrm{M}$. Together, these results indicated that Aspergillipeptide $\mathrm{D}$ has a significant antiviral effect against ACV-resistant HSV-1 strains.

\section{Mode of antiviral activity}

Next, we analyzed which step of HSV-1 life cycle was affected by Aspergillipeptide D. Plaque assay was 


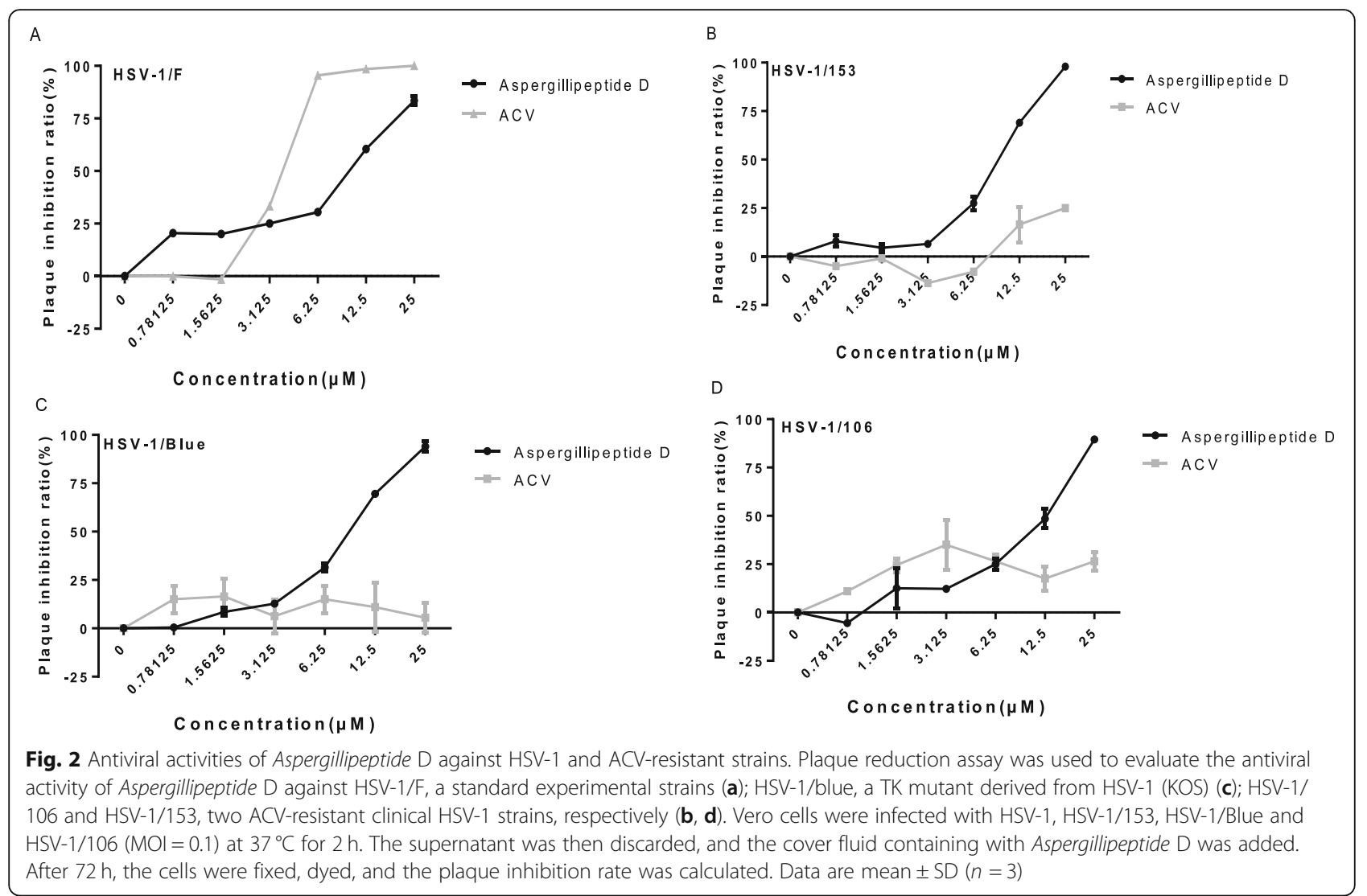

performed to demonstrate that Aspergillipeptide D significant reduced HSV-1 infection in a dose-dependent manner (Fig. 3a). Besides, the HSV-1-induced plaque size was largely reduced (Fig. 3b), implying the decreased virion production. Then viral inactivation assay, viral penetration assay, and viral attachment assay were performed, which showed that Aspergillipeptide D had no significant effect on viral inactivation, attachment and penetration (Fig. 3c-e). These results suggested that Aspergillipeptide D affected viral late infection events, such as replication and release.

\section{Effects of Aspergillipeptide D on viral gene and protein expression}

To determine whether Aspergillipeptide D affected viral DNA replication, viral DNA was extracted from Vero cells treated with or without Aspergillipeptide $\mathrm{D}$, and the copy number of UL47 was examined. As shown in (Fig. 4a), Aspergillipeptide D didn't affect the production of UL47. To analyze the effects of Aspergillipeptide D on HSV-1 gene expression, the mRNA expression levels of viral immediate-early gene (UL54), early gene (UL52), and late gene (UL27) were quantified at 3,6 , and $9 \mathrm{~h}$ pi., respectively (Fig. 4b). Interestingly, Aspergillipeptide D significantly reduced the expression of $U L 27$, without significant effect on the expression of UL54 and UL52, Consistently, western blotting assay demonstrated that Aspergillipeptide $\mathrm{D}$ reduced the protein level of viral late protein $\mathrm{gB}$ (encoded by viral late gene UL27) and did not affect viral immediately early protein ICP0, early protein ICP8, late protein VP5 and gD (Fig. 4c). Furthermore, immunofluorescent assay showed that the

Table 1 Antiviral activity of ACV and Aspergillipeptide D

\begin{tabular}{|c|c|c|c|c|c|}
\hline \multirow[t]{2}{*}{ Compound } & \multirow[t]{2}{*}{$\mathrm{CC} 50^{\mathrm{b}}(\mu \mathrm{M})$} & \multicolumn{4}{|l|}{$\mathrm{EC} 50^{\mathrm{C}}(\mu \mathrm{M})$} \\
\hline & & HSV-1/F & HSV-1/106 & HSV-1/153 & HSV-1/Blue \\
\hline$\overline{\mathrm{ACV}^{\mathrm{a}}}$ & $>500$ & $3.606 \pm 0.302$ & $46.234 \pm 15.335$ & $85.746 \pm 21.753$ & $273.742 \pm 20.826$ \\
\hline Aspergillipeptide D & $208.723 \pm 9.717^{* *}$ & $7.928 \pm 0.511$ & $10.486 \pm 0.929^{* *}$ & $8.277 \pm 1.249^{* *}$ & $7.9875 \pm 0.616^{* *}$ \\
\hline
\end{tabular}

${ }^{a}$ Acyclovir

b The CC50 (50\% cytotoxic concentration for Vero cells in lg/ml); mean \pm S.E

c The EC50 (Concentration of compound producing 50\% inhibition of virus-induced cytopathic effect)

**represents a significant difference compered with the control group 


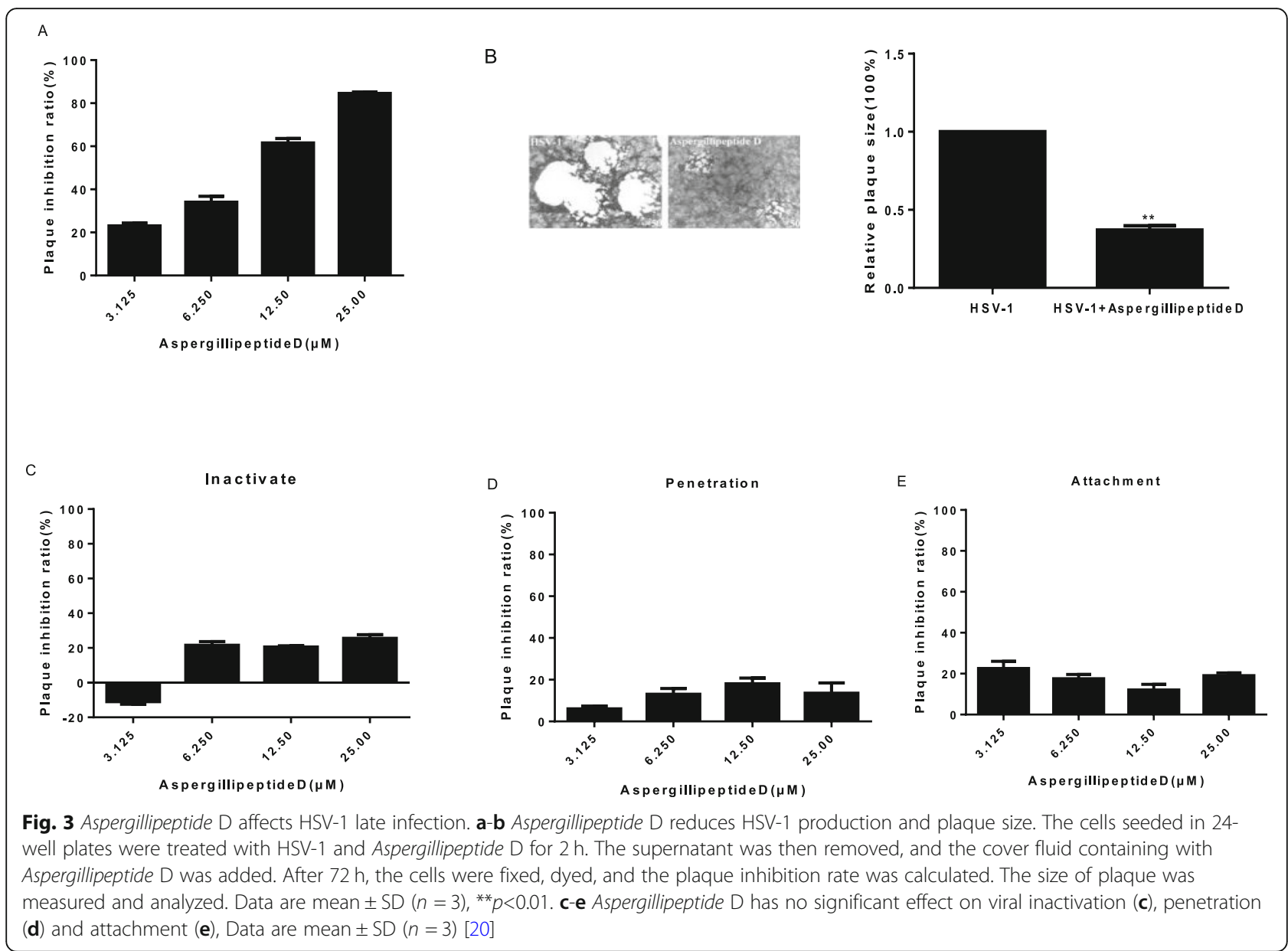

expression and the localization of gB in the endoplasmic reticulum and Golgi apparatus was largely reduced with the treatment of Aspergillipeptide D (Fig. 4e and f). Considering the fact that Aspergillipeptide D had no significant effect on viral attachment and penetration (Fig. 3c-f), it is reasonable to infer that Aspergillipeptide $\mathrm{D}$ inhibited $\mathrm{gB}$ to influence viral assembly, release and intercellular spread, as illustrated by the viral reduced plaque size (Fig. 3b). To confirm whether Aspergillipeptide D exerted its antiviral activity through $g B$, we constructed a HA-tagged gB plasmid and tested the effect of overexpression of $\mathrm{gB}$ on viral titer (Fig. $4 \mathrm{~g}$ ). Indeed, $\mathrm{gB}$ overexpression obviously enhanced HSV-1 infection and restored some of the virus production reduced by Aspergillipeptide D. In summary, these above results suggested that Aspergillipeptide D reduces the expression and location of viral gB to affect HSV-1 infection.

\section{Effect of Aspergillipeptide $\mathrm{D}$ on the interaction between the viral $\mathrm{gB}$ and cellular proteins}

Finally, we performed proteomic analysis to evaluate the effect of Aspergillipeptide D on gB. Different proteins interacted with $\mathrm{gB}$ during viral late stage were extracted by co-immunoprecipitation (Co-IP), and were then identified by mass spectrometry (MS). According to the Venn diagram, there were 78 proteins interacted with $g B$ protein in HSV-1 infection, the number of which was reduced to 37 in the presence of Aspergillipeptide D (Fig. 5a). Next, the COG (Cluster of Orthologous Groups of Proteins) annotation analysis was performed to predict the possible functions of these proteins, and we found that the reduction of gB-interacted proteins by Aspergillipeptide D were mainly involved in translation, ribosomal structure, biogenesis, posttranslational modification, protein turnover, chaperones and cytoskeleton (Fig. 5b). In addition, KEGG pathways enrichment analysis indicated that these reduced $\mathrm{gB}$-interacted proteins were mainly enriched in pathways associated with ribosome (Fig. 5c), tight junction, regulation of actin cytoskeleton and endocytosis (Fig. 5d). Among these proteins, integrin beta 1 that plays critical roles in three pathways maybe a key protein.

\section{Discussion}

Oceans provide tremendous resources for the discovery of potential therapeutic agents. In the last few decades, 


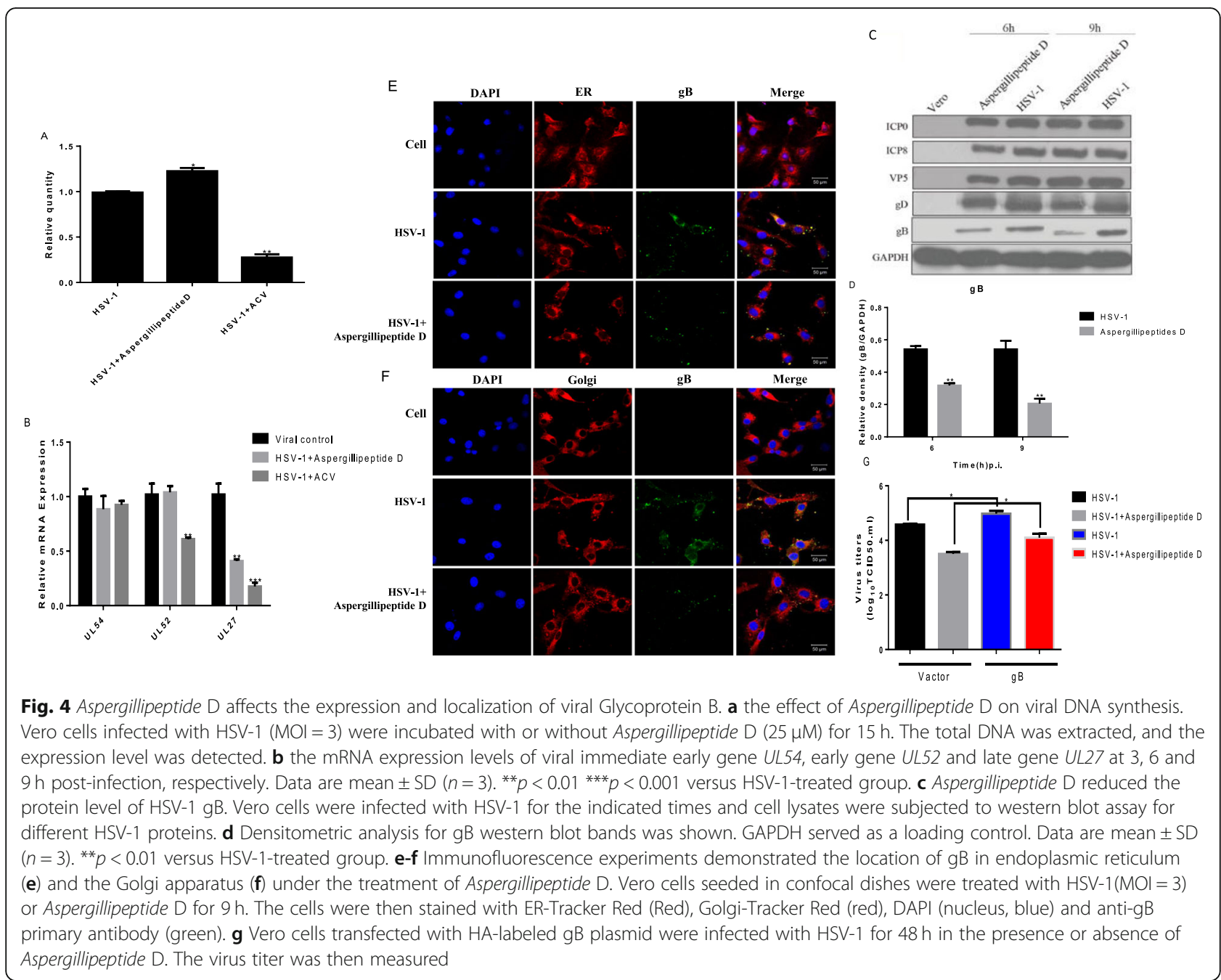

many interesting compounds have been found in marine organisms [21, 22]. Herein, we demonstrated that Aspergillipeptide D, a new cyclic pentapeptide obtained from the fungal strain Aspergillus sp. SCSIO 41501 [23], exhibited obvious antiviral activity against HSV-1 and ACV-resistant strains. We also investigated its possible mechanisms of antiviral action.

Plaque reduction experiments showed that Aspergillipeptide D had a significant antiviral effect in a concentrationdependent manner (Fig. 3a), but without significant effect HSV-1 early infection events, including inactivation, attachment and penetration. More detailed studies indicated that Aspergillipeptide D significantly reduced the gene and protein levels of viral late protein gB (Fig. 4). In addition, Aspergillipeptide $\mathrm{D}$ reduced the localization of $\mathrm{gB}$ in the endoplasmic reticulum and the Golgi apparatus.

Entry into target cells is the first step for virus infection [24]. The core entry machinery for herpesviruses is formed by the $\mathrm{gH}, \mathrm{gD}, \mathrm{gL}$ and $\mathrm{gB}$ proteins. The herpesvirus $\mathrm{gB}$ protein is a class III viral fusion protein $[25,26]$. Once $\mathrm{gB}$ is triggered, its fusion loops (FLs) insert into the target host cell lipid bilayer, followed by $\mathrm{gB}$ refolding to drive membrane merger and the onset of infection [26]. Our results showed that Aspergillipeptide D had no significant effect on viral inactivation, attachment and penetration, but could significantly reduce the expression of gB protein. These results suggested that Aspergillipeptide D affected the synthesis of gB protein to reduce HSV-1 intercellular spread, as viral plaque size was largely reduced (Fig. $3 \mathrm{~b}$ ). Such antiviral mechanism of Aspergillipeptide $\mathrm{D}$ is different from that of ACV, which may be responsible for the significant antiviral effects of Aspergillipeptide D on ACV-resistant strains (HSV-1/106, HSV-1/ Blue and HSV-1/153).

To further analyze the effect of Aspergillipeptide $\mathrm{D}$ on $\mathrm{gB}$, cellular proteins that interact with $\mathrm{gB}$ protein were identified (Fig. 5). Aspergillipeptide D significantly reduced the gB-interacted proteins involved in translation, ribosomal structure, biogenesis; posttranslational modification, protein turnover, chaperones and cytoskeleton. In 


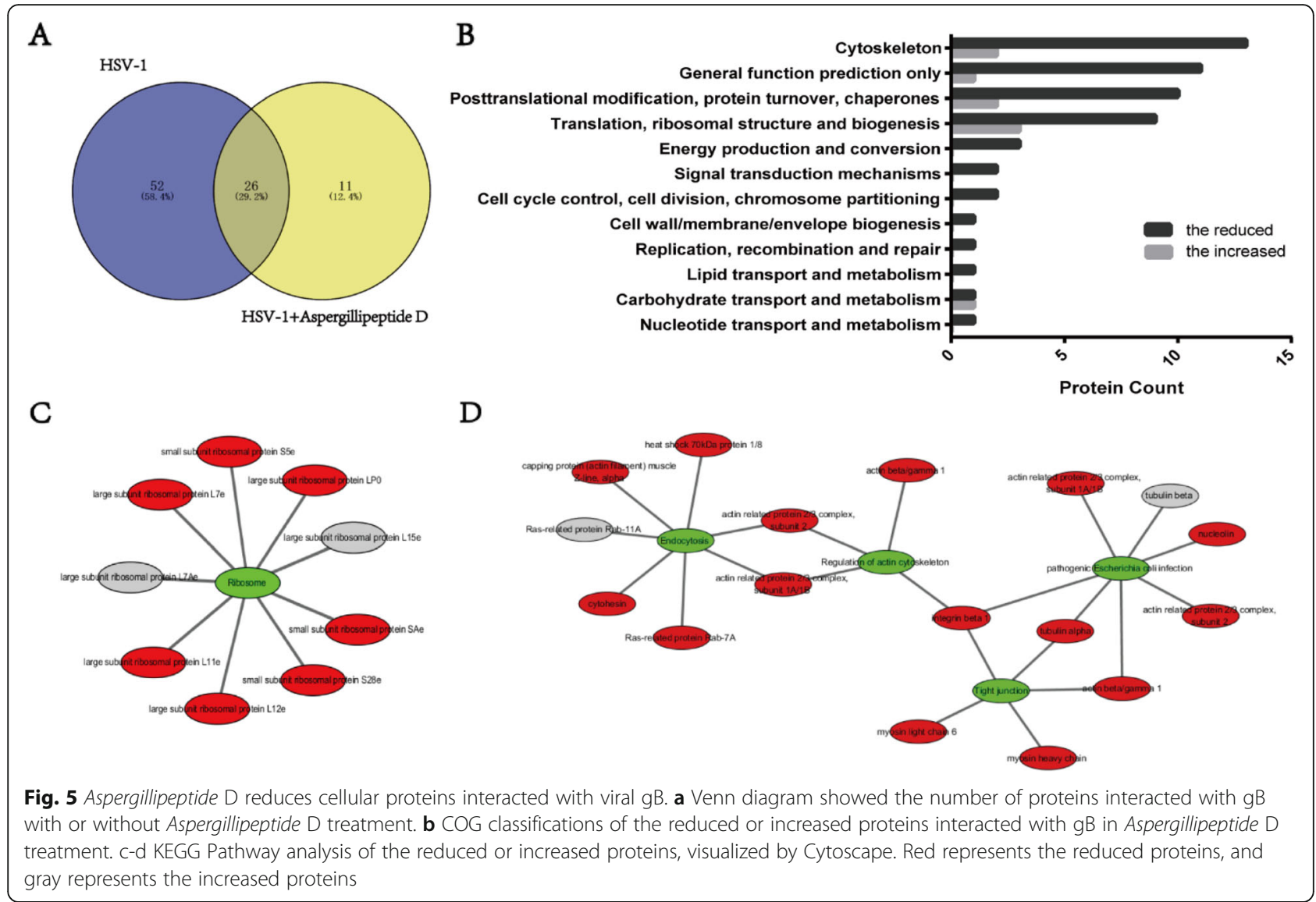

addition, KEGG pathways enrichment analysis indicated that these proteins were mainly enriched in pathways associated with ribosome, tight junction, regulation of actin cytoskeleton, pathogenic $E$. coli infection and endocytosis. Among them, integrin beta 1 that plays critical roles in three pathways maybe a key protein. Integrins are cell surface heterodimeric glycoproteins that contribute to a variety of functions, including cell-cell and cell-matrix adhesion and induction of signal transduction pathways [27]. Recently, it has been demonstrated that integrin beta 1 accumulated and formed a complex with CD98hc at the nuclear membrane in HSV-1-infected cells (26). Knockdown of integrin beta 1 induced aberrant accumulation of primary enveloped virions in the perinuclear space and in the membranous invagination structures adjacent to the nuclear membrane, implying that integrin beta 1 playing critical role in HSV-1 nuclear egress and assembly [28]. Further works are inspired to investigate whether Aspergillipeptide $\mathrm{D}$ affects the possible function of integrin beta 1 in HSV-1 late infection.

\section{Conclusion}

Summarizing these data, Aspergillipeptide D is assessed to be a potential candidate for HSV-1 therapy, especially for ACV-resistant strains.

\section{Abbreviations}

ACV: Acyclovir; Co-IP: Coimmunoprecipitation; CPE: Cytopathic effect; DMEM: Dulbecco's modified Eagle's medium; DMSO: Dimethyl sulfoxide; HSV-1: Herpes simplex virus 1; MOI: Multiplicity of infection; PBS: Phosphatebuffered saline; TCID 50 : 50\% tissue culture infective dose

\section{Acknowledgements}

The authors thank Shu-Hua Qi for providing the isolate of Aspergillipeptide D.

\section{Authors' contributions}

ZR, YW, ZW and JJ conceived and designed the study. JY, SQ provided the isolate of Aspergillipeptide D. ZW, JJ, XS, SQ and YJ performed the experiments and analyzed the data. ZW, FL and YW drew the graphs. ZW, JJ and KZ wrote the paper. All authors read and approved the final manuscript.

\section{Funding}

We are grateful for the financial support provided by the National Natural Science Foundation of China [grant numbers 81573471, 81673326] and the National Key Research and Development Program of China; the International Cooperation Program of Guangdong Province of China [grant number 2015A050502028]; the Industry-university Collaborative Innovative Major Projects of Guangzhou [grant number 201504291048224]; Science and Technology Planning Project of Guangdong Province, China [grant number

2016A040402033]; The Key Laboratory of Bioengineering Drugs of Guangdong Province [grant number 2014B030301050-5]; The Basic Research Project of Qinghai Province of China [2016-ZJ-712]; Guangdong Natural Science Foundation [2019A1515010046].

Availability of data and materials

All data from the current study are available from the corresponding author on request. 
Ethics approval and consent to participate

Not applicable.

\section{Consent for publication}

Not applicable.

\section{Competing interests}

The authors declare no conflict of interest. The funders had no role in the design of the study; in the collection, analyses, or interpretation of data; in the writing of the manuscript, or in the decision to publish the results. Consent for publication.

\section{Author details}

${ }^{1}$ Guangzhou Jinan Biomedicine Research and Development Center, National Engineering Research Center of Genetic Medicine, Jinan University, Guangzhou, Guangdong, China. ${ }^{2}$ School of Pharmaceutical Sciences, Health Science Center, Shenzhen University, Shenzhen, China. ${ }^{3}$ Key Laboratory of Plant Chemistry in Qinghai-Tibet Plateau, Qinghai University for Nationalities, Xining 810007, Qinghai, China. ${ }^{4}$ CAS Key Laboratory of Tropical Marine Bio-resources and Ecology, South China Sea Institute of Oceanology Chinese Academy of Sciences, 164 West Xingang Road, Guangzhou 510301, Guangdong, China.

Received: 19 July 2019 Accepted: 9 March 2020

Published online: 19 March 2020

\section{References}

1. Victor Shahin WH. The genome of HSV-1 translocates through the nuclear pore as a condensed rod-like structure. J Cell Sci. 2006;119:23-30.

2. Mettenleiter TC, Klupp BG, Granzow H. Herpesvirus assembly: an update. Virus Res. 2009;143:222-34.

3. Loret S, Guay G, Lippe R. Comprehensive characterization of extracellular herpes simplex virus type 1 virions. J Virol. 2008;82:8605-18.

4. Spear PG, Longnecker R. Herpesvirus entry: an update. J Virol. 2003;77: 10179-85.

5. Browne $H$, Bruun B, Whiteley A, Minson T. Analysis of the role of the membrane-spanning and cytoplasmic tail domains of herpes simplex virus type 1 glycoprotein D in membrane fusion. J Gen Virol. 2003;84:1085-9.

6. Pertel PE, Fridberg A, Parish ML, Spear PG. Cell fusion induced by herpes simplex virus glycoproteins $\mathrm{gB}, \mathrm{gD}$, and $\mathrm{gH}-\mathrm{gL}$ requires a $\mathrm{gD}$ receptor but not necessarily heparan sulfate. Virology. 2001;279:313-24.

7. Farnsworth A, Wisner TW, Webb M, Roller R, Cohen G, Eisenberg R, Johnson DC. Herpes simplex virus glycoproteins $\mathrm{gB}$ and $\mathrm{gH}$ function in fusion between the virion envelope and the outer nuclear membrane. Proc Natl Acad Sci U S A. 2007;104:10187-92.

8. Akhtar J, Shukla D. Viral entry mechanisms: cellular and viral mediators of herpes simplex virus entry. FEBS J. 2009:276:7228-36.

9. Backovic M, Jardetzky TS. Class III viral membrane fusion proteins. Curr Opin Struct Biol. 2009;19:189-96.

10. Piret J, Boivin G. Resistance of herpes simplex viruses to nucleoside analogues: mechanisms, prevalence, and management. Antimicrob Agents Chemother. 2011;55:459-72.

11. Kang HK, Seo CH, Park Y. Marine peptides and their anti-infective activities Mar Drugs. 2015;13:618-54.

12. Ngo DH, Vo TS, Ngo DN, Wijesekara I, Kim SK. Biological activities and potential health benefits of bioactive peptides derived from marine organisms. Int J Biol Macromol. 2012;51:378-83.

13. Kim S-K, Wijesekara I. Development and biological activities of marinederived bioactive peptides: a review. J Funct Foods. 2010;2:1-9.

14. Ma X, Nong X-H, Ren Z, Wang J, Liang X, Wang L, Qi S-H. Antiviral peptides from marine gorgonian-derived fungus Aspergillus sp. SCSIO 41501. Tetrahedron Lett. 2017:58:1151-5.

15. Wang Y, Wang Q, Zhu Q, Zhou R, Liu J, Peng T. Identification and characterization of acyclovir-resistant clinical HSV-1 isolates from children. J Clin Virol. 2011;52:107-12.

16. Ramakrishnan MA. Determination of $50 \%$ endpoint titer using a simple formula. World J Virol. 2016:5:85.

17. Jin F, Zhuo C, He Z, Wang H, Liu W, Zhang R, Wang Y. Anti-herpes simplex virus activity of polysaccharides from Eucheuma gelatinae. World J Microbiol Biotechnol. 2015;31:453-60.
18. Alvarez AL, Habtemariam S, Abdel Moneim AE, Melon S, Dalton KP, Parra F. A spiroketal-enol ether derivative from Tanacetum vulgare selectively inhibits HSV-1 and HSV-2 glycoprotein accumulation in Vero cells. Antivir Res. 2015;119:8-18.

19. Jin F, Ma K, Chen M, Zou M, Wu Y, Li F, Wang Y. Pentagalloylglucose blocks the nuclear transport and the process of Nucleocapsid egress to inhibit HSV-1 infection. Jpn J Infect Dis. 2016;69:135-42.

20. Harden EA, Falshaw R, Carnachan SM, Kern ER, Prichard MN. Virucidal activity of polysaccharide extracts from four algal species against herpes simplex virus. Antivir Res. 2009;83:282-9.

21. Mayer A, Rodríguez A, Taglialatela-Scafati O, Fusetani N. Marine Pharmacology in 2009-2011: Marine compounds with antibacterial, Antidiabetic, antifungal, anti-inflammatory, antiprotozoal, Antituberculosis, and antiviral activities; affecting the immune and nervous systems, and other miscellaneous mechanisms of action. Marine Drugs. 2013;11:2510-73.

22. Blunt JW, Copp BR, Munro MH, Northcote PT, Prinsep MR. Marine natural products. Nat Prod Rep. 2011;28:196-268.

23. Bao J, Zhang X-Y, Xu X-Y, He F, Nong X-H, Qi S-H. New cyclic tetrapeptides and asteltoxins from gorgonian-derived fungus Aspergillus sp. SCSGAF 0076. Tetrahedron. 2013;69:2113-7.

24. Harrison SC. Viral membrane fusion. Virology. 2015;479-480:498-507.

25. Baquero E, Albertini AA, Gaudin Y. Recent mechanistic and structural insights on class III viral fusion glycoproteins. Curr Opin Struct Biol. 2015;33:52-60.

26. Connolly SA, Jackson JO, Jardetzky TS, Longnecker R. Fusing structure and function: a structural view of the herpesvirus entry machinery. Nat Rev Microbiol. 2011;9:369-81.

27. Gahmberg CG, Fagerholm SC, Nurmi SM, Chavakis T, Marchesan S, Gronholm M. Regulation of integrin activity and signalling. Biochim Biophys Acta. 1790;2009:431-44.

28. Hirohata Y, Arii J, Liu Z, Shindo K, Oyama M, Kozuka-Hata H, Sagara H, Kato A, Kawaguchi Y. Herpes simplex virus 1 recruits CD98 heavy chain and beta1 integrin to the nuclear membrane for viral De-envelopment. J Virol. 2015;89:7799-812.

\section{Publisher's Note}

Springer Nature remains neutral with regard to jurisdictional claims in published maps and institutional affiliations.

Ready to submit your research? Choose BMC and benefit from:

- fast, convenient online submission

- thorough peer review by experienced researchers in your field

- rapid publication on acceptance

- support for research data, including large and complex data types

- gold Open Access which fosters wider collaboration and increased citations

- maximum visibility for your research: over $100 \mathrm{M}$ website views per year

At $\mathrm{BMC}$, research is always in progress.

Learn more biomedcentral.com/submissions 